\title{
The Lerner Index and Economic Efficiency*
}

\author{
R. G. Chambers' ${ }^{1}$, R. Färe ${ }^{2}$, S. Grosskopf ${ }^{2,3}$ \\ ${ }^{1}$ University of Maryland, College Park, USA \\ ${ }^{2}$ Oregon State University, Corvallis, USA \\ ${ }^{3}$ CERE, Umeå, Sweden \\ Email: rchambers@umd.edu, rolf.fare@orst.edu, Shawna.grosskopf@orst.edu
}

Received 11 October 2014; revised 10 November 2014; accepted 2 December 2014

Copyright (C) 2014 by authors and Scientific Research Publishing Inc.

This work is licensed under the Creative Commons Attribution International License (CC BY).

http://creativecommons.org/licenses/by/4.0/

c) (i) Open Access

\section{Abstract}

This short paper brings together two literatures: the first is the Lerner Index as a measure of imperfect competition familiar from industrial organization and the second is a measure of performance from the efficiency literature, namely the Nerlovian indicator. We show how these may be related and the resulting decomposition of the Lerner index which results.

\section{Keywords}

\section{Lerner Index, Nerlovian Indicator, Profit Efficiency}

In this short paper, we establish a relationship between the Lerner index-familiar from the industrial organization literature-and the less well-known Nerlovian indicator of profit efficiency. We prove that the Lerner index is the first order derivative of the Nerlovian indicator.

We also show that the Lerner index can be decomposed into three components: i) cost elasticity, ii) Farrell output technical efficiency (Farrell, 1957) [1] and iii) return to the dollar (Georgescu-Roegen, 1951) [2].

We begin with the Lerner index, which as Lerner put it, is the

“...formula that I wish to put forward as a measure of monopoly power. If $P=$ price and $C=$ marginal cost, then the index of the degree of monopoly power is $\frac{P-C}{P}$ ” Lerner (1934, p. 169) [3].

With respect to this index of monopoly power, Samuelson (1964, p. 173) [4] wrote

"Today this may seem simple, but I can testify that no one at Chicago or Harvard could tell me in 1935 why $P=M C$ was a good thing, and I was a persistent Diagenes”.

Turning to the Nerlovian indicator (Chambers, Chung and Färe, 1998) [5]; it was introduced as a measure of profit efficiency, specifically it is the normalized difference between maximal profit and observed profit. It is

*We thank V. Tremblay for his comments on an earlier draft.

How to cite this paper: Chambers, R.G., Färe, R. and Grosskopf, S. (2014) The Lerner Index and Economic Efficiency. Theoretical Economics Letters, 4, 803-805. http://dx.doi.org/10.4236/tel.2014.49101 
dual to the shortage function (Luenberger, 1992) [6], or equivalently to the directional technology distance function (Chambers, Chung and Färe, 1998) [5].

To continue, let $\Pi(p, w)$ be a profit function, with input prices $w$ and output prices $p$. Denote observed profit by $\Pi^{o}$, the input and output directional vectors by $g_{x}$ and $g_{y}$, respectively. The Nerlovian indicator is then defined as

$$
N=\frac{\Pi(p, w)-\Pi^{o}}{p g_{y}+w g_{x}} .
$$

In our case we assume that there is a single output and output price and that the cost minimization problem is solved so that $C(y, w)$ is a cost function. In addition we take $g_{x}=0$ and $g_{y}=1$, then the Nerlovian indicator reads as

$$
N=\max _{y} \frac{p y-C(y, w)-\Pi^{o}}{p \cdot 1}
$$

The first order condition is

$$
\frac{p-\partial C(y, w) / \partial y}{p}=L
$$

which is the Lerner Index.

In addition to showing that the Lerner index is the first order condition of the Nerlovian profit indicator we see that the index is normalized by the output price rather than the marginal cost.

Let us recall some basic notions from duality theory, specifically the duality between Shephard's 1970 output distance function and the revenue function. We begin with technology; thus if

$$
P(x)=\{y: x \text { can produce } y\}
$$

with $x \in \mathfrak{R}_{+}^{N}$ being the input vector and $y \geq 0$ the single output, then the output distance function is

$$
D_{o}(x, y)=\inf \{\theta: y / \theta \in P(x)\}
$$

and the corresponding revenue function is given by

$$
R(x, p)=\max _{y}\left\{p y: D_{o}(x, y) \leq 1\right\} .
$$

The distance function may be retrieved from the revenue function by optimizing over $p^{1}$,

$$
D_{o}(x, y)=\sup _{p}\{p y: R(x, p) \leq 1\} .
$$

From this duality it follows that

and thus

$$
p y=y D_{o}(x, 1) \cdot R(x, P)
$$

$$
p=D_{o}(x, 1) \cdot R(x, p) .
$$

Note that $D_{o}(x, y)=y D_{o}(x, 1)$ in the single output case due to homogeneity of the output distance function in $y$.

Using (9) we may write the Lerner Index from (3) as

where:

$$
\begin{aligned}
L & =\frac{p-\partial C(y, w) / \partial y}{p}=1-\frac{\partial C(y, w)}{\partial y} \frac{1}{D_{o}(x, 1) \cdot R(x, p)} \\
& =1-\frac{\partial C(y, w)}{\partial y} \frac{y C(y, w)}{y C(y, w) D_{o}(x, 1) \cdot R(x, p)} \\
& =1-\epsilon \cdot \frac{1}{D_{o}(x, y)} \cdot \frac{1}{R(x, p) / C(y, w)}
\end{aligned}
$$

${ }^{1}$ See Färe and Primont (1994) for an exposition of Shephard's duality theories. 
- $\epsilon=\frac{\partial C(y, w)}{\partial y} \frac{y}{C(y, p)}$ is the cost elasticity

- $\frac{1}{D_{o}(x, y)}$ is the Farrell output measure of technical efficiency, and

- $R(x, p) / C(y, w)$ is the Georgescu-Roegen "return to the dollar".

Thus the Lerner Index may be deduced from a measure of profit efficiency—-the Nerlovian Indicator—and may be decomposed into three further economic performance measures. We leave generalization to the multiple output case to future research.

\section{References}

[1] Farrell, M.J. (1957) The Measurement of Productive Efficiency. Journal of the Royal Statistical Society Series A, General, 120, 253-281. http://dx.doi.org/10.2307/2343100

[2] Georgescu-Roegen, N. (1951) The Aggregate Linear Production Function and Its Application to the Von Neumann Economic Model. In: Koopmans, T., Ed., Activity Analysis of Production and Allocation, Wiley, New York.

[3] Lerner, A.P. (1934) The Concept of Monopoly and the Measurement of Monopoly Power. The Review of Economic Studies, 1, 157-175. http://dx.doi.org/10.2307/2967480

[4] Samuelson, P.A. (1964) A.P. Lerner at Sixty. The Review of Economic Studies, 31, 169-178. http://dx.doi.org/10.2307/2295906

[5] Chambers, R.G., Chung, Y. and Färe, R. (1998) Profit, Directional Distance Functions, and Nerlovian Efficiency. Journal of Optimization Theory and Applications, 98, 351-364. http://dx.doi.org/10.1023/A:1022637501082

[6] Luenberger, D.G. (1992) New Optimality Principles for Economic Efficiency and Equilibrium. Journal of Optimization Theory and Applications, 75, 221-264. http://dx.doi.org/10.1007/BF00941466 
Scientific Research Publishing (SCIRP) is one of the largest Open Access journal publishers. It is currently publishing more than 200 open access, online, peer-reviewed journals covering a wide range of academic disciplines. SCIRP serves the worldwide academic communities and contributes to the progress and application of science with its publication.

Other selected journals from SCIRP are listed as below. Submit your manuscript to us via either submit@scirp.org or Online Submission Portal.
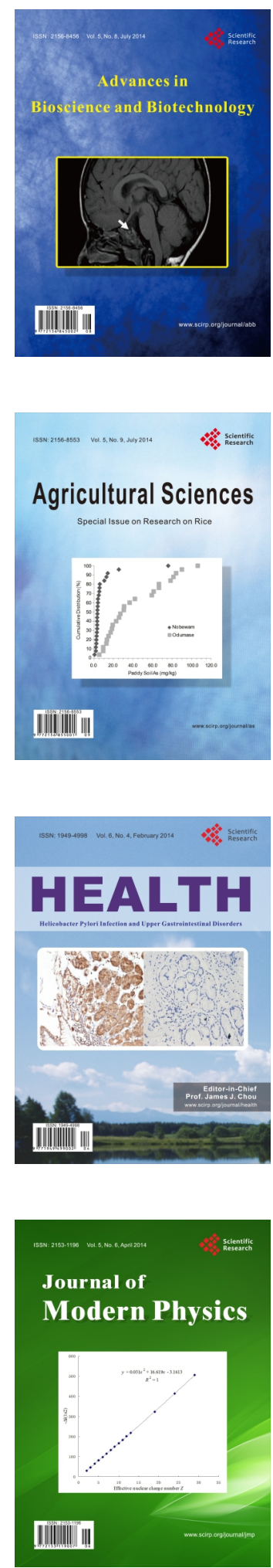
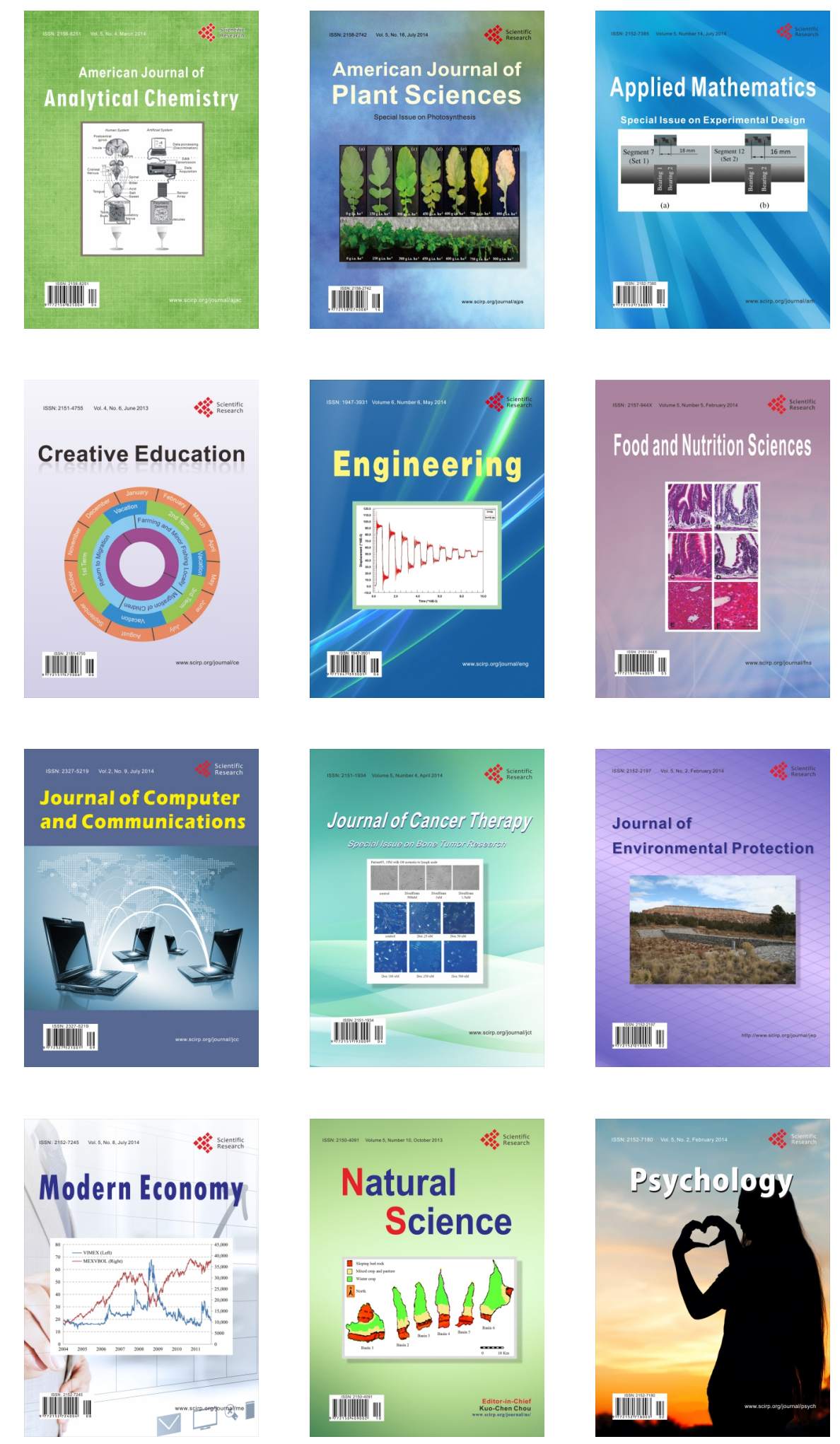